\title{
Vrouwenbeelden en genderrepresentatie in een leergang Nederlands voor anderstaligen
}

\begin{abstract}
This article focuses on the representation of women and images of females as an articulation of diversity in textbooks of Dutch as a foreign language, Code Plus 1 and Code Plus 2. The central research questions are: How are female characters, next to male characters, represented in the selected textbooks? Do the textbooks present gender stereotypes or do they rather question them?
\end{abstract}

Keywords: diversity, gender, images of females, representation, textbooks

\section{Inleiding}

In deze studie ligt de focus op de representatie van vrouwen in leergangen. Meer specifiek doet dit artikel verslag van onderzoek naar de vrouwelijke personages als een dimensie van diversiteit in leermiddelen Nederlands voor anderstaligen. De aandacht voor diversiteit in de recente leergangen Nederlands als Vreemde Taal (hierna: NVT) of Nederlands als Tweede Taal (hierna: NT2) komt door een impliciete benadering aan bod die de keuzes van teksten en beeldfragmenten omvat.

Het concept 'diversiteit' kan in een 'smalle' of in een 'brede' definitie worden geïntroduceerd. Cristel van de Ven en Carsten De Dreustellen in Denkfouten over diversiteit:

Wetenschappers onderscheiden een smalle en een brede definitie van diversiteit. De smalle definitie gaat over specifieke categorieën zoals leeftijd, etniciteit of geslacht. De brede definitie stelt dat alle mogelijke verschillen onder de noemer van diversiteit vallen, zowel demografische als psychologische als organisatorische (Van de Ven \& De Dreu 2017).

In de 'smalle' definitie ligt de nadruk op de etnisch-culturele verschillen, terwijlde 'brede' definitie van diversiteit meerdere kenmerken omvat, zoals sociaal milieu, religie en geslacht. Cultuur wordt als instituut beschouwd als een belangrijke plaats waar we direct kennis kunnen maken met aspecten van diversiteit en 
waar we onszelf en anderen leren kennen (Kellner 1995). Als zichtbare artefacten van cultuur kunnen tekstboeken culturele betekenissen creëren en representeren betreffende diversiteit, en hier meer bepaald betreffende genderdiversiteit. Het corpus van dit onderzoek is samengesteld uit tekstboeken Code plus I en II die als een representatieve afspiegeling van de geanalyseerde genderbeelden worden beschouwd. Leerboeken zijn typisch een hybride genre ofwel "a blurred genre" (Geertz 1983) omdat ze zich voordoen als leermiddelen maar tegelijk een cultuurbeeld presenteren en ook een krachtig visueel medium zijn.

\section{Onderzoeksvragen}

In dit artikel willen we op basis van een analyse nagaan hoe vrouwen aan bod komen in tekstboeken Nederlands voor anderstaligen. Daarbij wordt uitgegaan van de resultaten van een analyse van één geselecteerde leergang, Code Plus Deel 1 en Deel 2. De centrale onderzoeksvragen zijn daarbij:

- Hoe worden vrouwelijke personages naast mannelijke personages gerepresenteerd in de geselecteerde leergang?

- Welk(e) vrouwenbeeld(en) brengt de leergang?

In aanvulling op deze hoofdvragenen om die te specificeren zijn een aantal deelvragen geformuleerd:

- Op welke wijze worden vrouwelijke personages in het algemeen afgebeeld, welke rol spelen ze en beantwoordt deze rol aan een bepaalde stereotype?

- In welke rollen worden vrouwelijke personages in de illustraties afgebeeld?

- Komen er individuele en collectieve representaties aan bod?

- Welke (vrouwen) beelden ontbreken? Wat wordt niet gerepresenteerd?

- In welke mate gaat de leergang uit van een positief perspectief op (gender) diversiteit?

Representatie is een van de centrale concepten in deze studie. In teksten en beelden in de leergangen en lesmethodes NT2/NVT worden constant representaties van vrouwen en mannen geproduceerd. Volgens Malik (2002: 24) heeft het concept van representatie twee betekenissen:

1. het proces van representatie van iets/iemand door een ander iets/iemand. Deze betekenis gaat uit van de veronderstelling dat iets of iemand symbolisch de plaats van iets/iemand anders kan innemen;

2. het proces waarbij een bepaald beeld van iemand wordt gereproduceerd. In deze betekenis gaat het om representatie door middel van afbeelding en beschrijving van iemand/iets via taalgebruik, zowel mondeling als visueel.

In deze studie staat de tweede betekenis van representatie centraal. Tekstboeken distribueren continu beelden van verschillende individuen en groepen in de samenleving. Beelden betekenen hier niet alleen de letterlijke beelden en afbeeldingen, zoals foto's en beeldfragmenten als paratekstuele elementen, maar vooral de manier waarop de personages worden beschreven. 


\section{Methode}

De benadering is een combinatie van een kwalitatieve en kwantitatieve studie. Als methode zal ik voornamelijk gebruikmaken van beeldanalyse en tekstanalyse, dit wil zeggen, een bestudering van de visuele beelden en een tekstuele inhoudsanalyse die de manieren onderzoekt waarop de personages worden voorgesteld.

Van de kwantitatieve benadering zijn de objectiviteit en de herhaalbaarheid de evidente voordelen. Tegelijkertijd moet er ook rekening worden gehouden met de beperkingen van deze methode. McQuail (2000: 327) wijst terecht op een van de essentiële tekortkomingen, namelijk het ontbreken van de interpretatie van de onderzoeker. In dit geval zal een kwalitatieve benadering de tekortkomingen van de kwantitieve methode compenseren.

Vaak gaat het bij de genderrepresentatie van vrouwen over stereotypen. Het focussen op stereotypen heeft bij bestuderen van representaties vaak nadelen. Het stereotypenonderzoek schiet tekort in het waarnemen van de dynamiek en subtiliteit van de representatie (Cottle 2000: 12). Om deze reden is de analyse vooral gericht op de positie(s) van de vrouwelijke personages in de structuur van de leergang en niet zozeer op bepaalde stereotype beelden.

Als hoofdcategorie voor de kwantitatieve analyse is gekozen voor de zichtbaarheid van vrouwen en hun rol in teksten en beelden (één van de categorieën van Porecca 1984). Zichtbaarheid verwijst naar de daadwerkelijke aanwezigheid van vrouwelijke personages, zowel in de teksten als in de illustraties en de videofragmenten, in vergelijking met de mannelijke personages.

Voor de kwalitatieve analyse is gekozen voor de volgende categorieën:

1. Relatie en gezin; huishoudelijk werk en kinderzorg

2. Arbeidsmarktparticipatie en werkrollen

3. Opleiding en vorming

4. Vrijetijdsbesteding, interesses en hobby's

5. Uiterlijk

6. Bekende (Nederlandse) vrouwen

7. Multiculturele diversiteit

In studies over vrouwenrepresentatie in tekstboeken is de aandacht gegaan naar stereotypen of, in meer recente onderzoeken, naar criteria (Rifkin 1998). Dit onderzoek is op criteria gebaseerd (zie Schmitz 1975, 1984; Sunderland 1994), omdat het in de eerste plaats op de mate van zichtbaarheid en integratie van vrouwen in tekstboeken en van hun afbeelding is gericht. 


\section{Selectie van het onderzoeksmateriaal}

Dit artikel beperkt zich tot de analyse van één leergang, CODE Plus Deel 1 en Deel 2, een totaalpakket voor hoogopgeleide anderstaligen om Nederlands als tweede of vreemde taal te leren. Elk van de vier delen bestaat uit een takenboek met audio- en videomateriaal. CODE Plus is een complete basisleergang waarin veel aandacht wordt besteed aan uitwisseling van (inter)culturele ervaringen en aan informatie over de Nederlandse samenleving. De taal wordt niet alleen als code beschouwd maar ook culturele informatie en leefregels komen uitvoerig aan bod. Het auteurscollectief bestaat voornamelijk uit vrouwen.

\section{Zichtbaarheid en genderevenwicht - categorieën personages}

Het tekstboek kent geen unieke held. Er zijn een aantal hoofdpersonages die allemaal een rol spelen. Naast de hoofdpersonages figureren er een aantal secundaire personages die geen belangrijke rol spelen en deel van het decor uitmaken, en daarnaast ook figuranten, toevallige figuren van een episodisch karakter.

Uit de kwantitieve analyse blijkt dat de percentages vrouwelijke en mannelijke personages vrijwel gelijk verdeeld zijn. Er is bovendien een aanzienlijk aantal genderneutrale personages.

Tabel 1. Tekstuele zichtbaarheid

\begin{tabular}{|l|c|c|c|c|}
\hline $\begin{array}{c}\text { CODE Plus } \\
\text { Deel 1 }\end{array}$ & $\begin{array}{c}\text { Hoofdperson- } \\
\text { ages }\end{array}$ & Bijfiguren & Figuranten & Totaal \\
\hline $\begin{array}{l}\text { Vrouwelijke } \\
\text { personages }\end{array}$ & $5(45,4 \%)$ & $43(51,8 \%)$ & $32(46,4 \%)$ & $80(49,1 \%)$ \\
\hline $\begin{array}{l}\text { Mannelijke } \\
\text { personages }\end{array}$ & $6(54,5 \%)$ & $40(48,2 \%)$ & $37(53,6 \%)$ & $83(50,9 \%)$ \\
\hline
\end{tabular}

Tabel 2. Tekstuele zichtbaarheid

\begin{tabular}{|l|c|c|c|c|}
\hline \multicolumn{1}{|c|}{$\begin{array}{c}\text { CODE Plus } \\
\text { Deel 2 }\end{array}$} & $\begin{array}{c}\text { Hoofdperson- } \\
\text { ages }\end{array}$ & Bijfiguren & Figuranten & Totaal \\
\hline $\begin{array}{l}\text { Vrouwelijke } \\
\text { personages }\end{array}$ & $9(50 \%)$ & $30(45,4 \%)$ & $50(46,3 \%)$ & $89(48,6 \%)$ \\
\hline $\begin{array}{l}\text { Mannelijke } \\
\text { personages }\end{array}$ & $9(50 \%)$ & $36(54,5 \%)$ & $58(53,7 \%)$ & $94(51,4 \%)$ \\
\hline
\end{tabular}


Tabel 3. Tekstuele zichtbaarheid

\begin{tabular}{|l|c|c|c|}
\hline \multicolumn{1}{|c|}{ Personages } & $\begin{array}{c}\text { CODE Plus Tak- } \\
\text { enboek deel 1 }\end{array}$ & $\begin{array}{c}\text { CODE plus Tak- } \\
\text { enboek deel 2 }\end{array}$ & Totaal \\
\hline Vrouwelijke & $80(49,1 \%)$ & $89(48,6 \%)$ & $169(48,8 \%)$ \\
\hline Mannelijke & $83(50,9 \%)$ & $94(51,4 \%)$ & $177(51,1 \%)$ \\
\hline Totaal & 163 & 183 & 346 \\
\hline
\end{tabular}

Tabel 4. Visuele zichtbaarheid

\begin{tabular}{|l|c|c|c|}
\hline \multicolumn{1}{|c|}{ Personages } & $\begin{array}{c}\text { CODE Plus Tak- } \\
\text { enboek deel 1 }\end{array}$ & $\begin{array}{c}\text { CODE plus Tak- } \\
\text { enboek deel 2 }\end{array}$ & Totaal \\
\hline Vrouwelijke & $53(54,6 \%)$ & $54(56,8 \%)$ & $107(55,7 \%)$ \\
\hline Mannnelijke & $44(45,4 \%)$ & $41(43,1 \%)$ & $85(44,3 \%)$ \\
\hline Totaal & 97 & 95 & 192 \\
\hline
\end{tabular}

De vrouwen zijn in de geanalyseerde leergang kwantitatief duidelijk zichtbaar, zowel tekstueel als visueel, en er is ook een genderevenwicht vast te stellen.
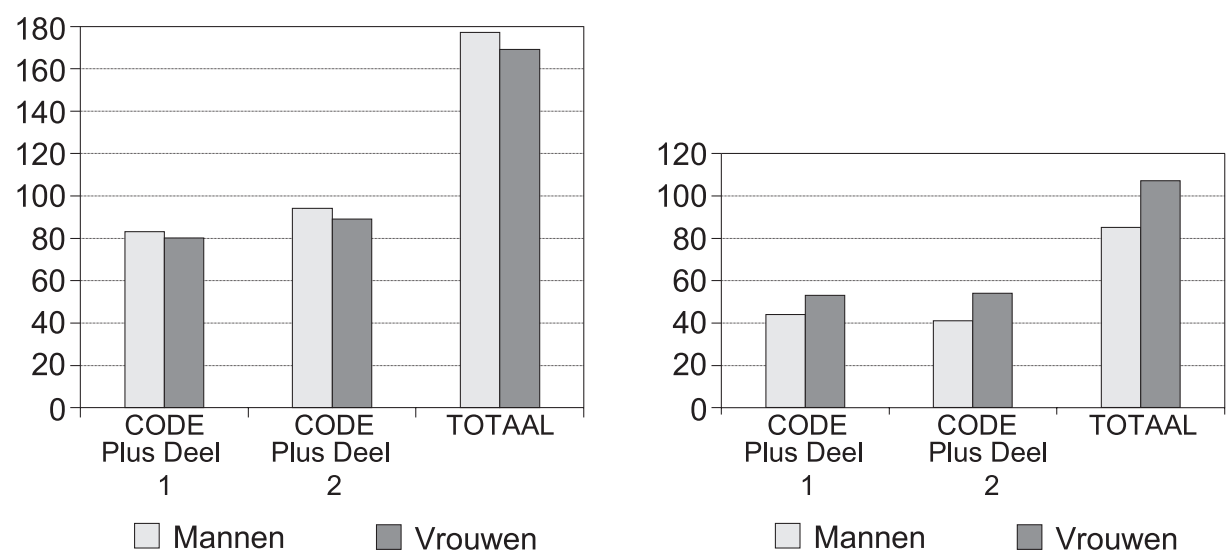

Tabel 5. Aantal vrouwelijke en mannelijke personages in teksten en beelden

\section{Vrouwenbeelden en rollencombinatie - relatie en gezin}

Het bekende eenzijdige beeld van het traditionele gezin waarin de man het inkomen verdient en de vrouw het huishoudelijk werk doet, de kinderen verzorgt en opvoedt, past niet bij het algemene beeld van de vrouwen in deze leergang. Er zijn geen voorbeelden van het klassieke gezinsmodel waarin de man als voltijds 
kostwinner fungeert en de vrouw als voltijds moeder, hoewel bij twee vrouwelijke personages hun rol als moeders en partners worden vermeld. Het gaat hier om twee vrouwelijke personages met een migrantenachtergrond die wel gezinsverplichtingen hebben, maar van wie niet expliciet wordt vermeld dat ze ook werkverplichtingen buitenshuis hebben: Malika, 50 jaar, getrouwd, met 4 kinderen, afkomstig uit Marokko (Code Plus 2: 89) en Dewi, 32 jaar, getrouwd, met 2 kinderen (Code Plus 1).

Bij vrouwelijke personages komt het combineren van de rollen van partner, moeder en werknemer vaak voor. Het standaardpatroon, vrouwen die relatie, werk en ouderschap combineren, is het meest voorkomende patroon. De duidelijk naar sekse afgebakende gezinsstructuren zijn vervaagd.

Vrouwen hebben een vrije keuze voor hun levensstijl: trouwen, kinderen krijgen en voor het gezin zorgen is niet de enige optie. Naast het vaak voorkomende beeld van getrouwde vrouwen met één of twee kinderen zijn ook ongetrouwde, kinderloze of gescheiden vrouwelijke personages afgebeeld, zoals mevrouw Geersten, 40 jaar, alleenstaande moeder van één kind (Code Plus 1: 96-97), of Ilse, die een drukke baan heeft en zelf geen kinderen heeft (Code Plus 2: 151-152). Jacky Neslo, 35 jaar, gescheiden met één kind, wordt als een onafhankelijke moderne vrouw geportretteerd, met een sterke en zelfverzekerde uitstraling en een goede sociaal-economische status. Jacky vertelt: "Soms zeggen mensen tegen mij: 'Jij hebt het goed. En dat is ook zo: Ik heb een kind, een huis, een auto en een baan' (Code Plus 2: 89).

Het beeld van het tweeverdienersgezin gaat gepaard met veranderingen in de rolverdeling tussen man en vrouw. Mannen nemen thuis taken voor hun rekening (Dewi Chen doet boodschappen, Code Plus 1: 60, Pieter doet ook boodschappen voor zijn gezin, p. 61, in de agenda van Eddy staat dat hij zijn dochter Jessica naar de moeder Regine moet brengen). De verdeling van huishouidelijke taken is in een deel van de gerepresenteerde gezinnen egalitair en er is sprake van een minder stereotype taakverdeling, waarbij de mannen intensiever zijn betrokken bij de kinderverzorging, zo heeft bijvoorbeeld de moeder van Anna een gesprek met meester Peter, maar ook de vader van Victor heeft een zelfde gesprek over het rapport van zijn kind op de basisschool.

Niet alleen gezinnen met een gelijke taakverdeling worden geportretteerd, maar ook gezinnen waarin vrouwen een groot deel van de huishoudelijke en zorgtaken verrichten. Het gezin van Martijn en Janneke en hun zoon Gijs is een voorbeeld van een huishouden waarin de vrouw de huishoudelijke taken grotendeels voor haar rekening neemt: "Janneke doet de boodschappen en ze kookt ook het eten" (Code Plus 1: 73). De participatie van de man beperkt zich tot consumeren. Deze ongelijke taakverdeling wordt ook extra benadrukt in de vragen bij de tekst: "Wat doet Martijn? c) eten" (Code Plus 1: 72).

Niet in alle gezinnen heeft de emancipatie van de vrouw en haar verschijnen op de arbeidsmarktechter een positieve impact op de taakverdeling gehad. Deze 
ontwikkeling kan tot een dubbele last voor de vrouw leiden. In de tekst Hotel Mama is gratis vertelt Cindy: "Mijn moeder doet bijna alles. En ze werkt ook als lerares op een middelbare school" (Code Plus 2: 115).

Er worden ook vrouwen geportetteerd voor wie het gezin niet de enige optie is en die bewustde keuze maken om onafhankelijk te zijn. In plaats van het clichébeeld van de verlaten vrouw wordt de lezer met het personage van de verlaten man geconfronteerd: "De vrouw van Antonio is niet meer bij hem. Het huis is te groot. De tuin is te groot" (Code Plus 1: 96).

Een deromantisering van de traditionele bruiloft komt aan bod in de advertentie van Barbara die haar trouwjurk verkoopt: "barbara.halla@hotmail.com Trouwjurk een keer gedragen, z.g.a.n., koopje: 200 euro" (Code plus 2: 10).

\section{Beroepen en activiteiten - arbeidsparticipatie/ werkrollen/carrièrevrouwen}

Uit de de kwantitatieve analyse blijkt dat vrouwen en mannen in de leergang in diverse beroepsrollen worden geportretteerd.

Tabel 6. Beroepen van vrouwelijke en mannelijke personages

\begin{tabular}{|l|l|}
\hline Beroepen van vrouwelijke personages & Beroepen van mannelijke personages \\
\hline Docente/Lerares $\times 7$ & Docent $\times 3$ \\
\hline Arts & Arts $\times 3$ \\
\hline Manager & Manager $\times 2$ \\
\hline Stewardess & Pizzeria medewerker \\
\hline Vertaler $\times 3$ & Schilder $\times 3$ \\
\hline Administratief medewerker $\times 2$ & Administratief medewerker \\
\hline Zangeres $\times 2$ & Muzikant \\
\hline Verkoper $\times 2$ & Verkoper $\times 4$ \\
\hline Serveerster & Ober $\times 2$ \\
\hline Secretaresse & DJ $\times 2$ \\
\hline Kassamedewerker & Monteur \\
\hline Verpleegkundige & Verpleegkundige \\
\hline Eigenaar familiebedrijf & Eigenaar familiebedrijf \\
\hline & Designer \\
\hline & Buschauffeur \\
\hline & Rij-instructeur \\
\hline
\end{tabular}

De arbeidsparticipatie van de vrouwelijke personages, getrouwde vrouwen met kinderen, blijkt hoog. De mogelijkheid om parttime te werken (vooral van getrouwde vrouwen met kinderen) en flexibiliteit in arbeidstijden maken het mogelijk voor Margreet (Code Plus 2: 47) om gezin en werk te combineren. Margreet heeft een baan in de thuiszorg: "Twee tot drie nachten per week zorg ik voor men- 
sen die 's nachts niet alleen kunnen zijn. Mijn werktijden zijn van 23:00 tot 7:00 uur" (Code Plus 2: 154). En er wordt expliciet gesteld: "Nederland heeft een hoog percentage vrouwen die in deeltijd werken" (Code Plus 2: 167).

De tekst Mannenwerk - vrouwenwerk (Code Plus 2: 167-169) behandelt expliciet het onderwerp 'vrouwenberoepen' en 'mannenberoepen' met de daarmee verbonden taken, zoals die nog steeds bestaan en nog steeds gedomineerd worden door vrouwen of mannen die daarin van oudsher werkzaam waren. Ook de ongelijke beloning van mannen en vrouwen komt aan bod. Hier gaat het om een collectieve representatie van vrouwen als een benadeelde groep.

De carrière van de vrouw vormt een belangrijk deel van het narratief. Vrouwelijke personages hebben ook niet-traditionele vrouwenberoepen", zoals bij voorbeeld 'de manager' Ilse en ze zijn al, of proberen om financiëel onafhankelijk te zijn door een baan te nemen of door een opleiding te volgen. Dat geldt bijvoorbeeld voor Margareth de Vries-Wilson, uit Sydney, Australië, die sinds 12 jaar in Nederland woont en freelance vertaler is: "Nu de kinderen groter zijn, zoek ik een baan buitenshuis (...) ik wil niet meer dan twintig uur per week werken" (Code Plus 2: 159).

Jenny Geertsema (Code Plus 2: 25), secretaresse, vroeger vertaler Engels, volgt nu een opleiding tot fysiotherapeut (Code Plus 2: 145). Voor Thérèse van Staveren (Code Plus 2: 29), lerares, speelt de werktevredenheid zelfs een grotere rol dan het salaris: "Ik doe mijn werk heel graag. Ik verdien niet zo goed, maar dat vind ik geen probleem. Het belangrijkste is dat ik mijn werk met plezier doe" (Code Plus 2: 144).

\section{Opleiding en vorming}

Tabel 7. Opleidings- en studiekeuze van vrouwelijke en mannelijke personages

\begin{tabular}{|l|l|}
\hline \multicolumn{1}{|c|}{ Vrouwelijke personages } & \multicolumn{1}{c|}{ Mannelijke personages } \\
\hline Tandheelkunde & Kapper \\
\hline Kinderverpleegkundige & Student $\times 5$ \\
\hline Studente onbepaalde studierichting $\times 2$ & Biologie \\
\hline Fysiotherapeut $\times 2$ & Journalistiek \\
\hline Geneeskunde & Rechten \\
\hline NT2-cursus $\times 2$ & NT2 cursus $\times 4$ \\
\hline Rijopleiding $\times 4$ & Rijopleiding $\times 4$ \\
\hline Vertaalopleiding & \\
\hline
\end{tabular}


De vertegenwoordiging van mannen en vrouwen die met hun professionele ontwikkeling bezig zijn blijkt evenwichtig te zijn. De onderwijs- en opleidingsmogelijkheden blijken voor de vrouwelijke personages in de leergang relevant te zijn. Neylan, uit Turkije, studeert tandheelkunde, Liza wil kinderverpleegkundige worden, Alexandra wil fysiotherapeut worden, Cindy studeert geneeskunde, Margareth de Vries-Wilson heeft een vertaalopleiding aan de Universiteit van Amsterdam gedaan (Code Plus 2).

Vrouwelijke personages met gezin en kinderen willen ook buiten de huishoudelijke sfeer actief zijn en ze vinden de mogelijkheden om hun opleiding voort te zetten belangrijk: "Ik heb een jaar gewerkt en kreeg toen twee kinderen. Die zitten nu op de basisschool. Ik ga terug naar de middelbare school" (Code Plus 2: 98).

\section{Vrijetijdsbesteding en hobby's}

Vrije tijd vormt binnen bepaalde sociale en culturele contexten een belangrijk aspect van de eigen identiteit en geeft zo inzicht in de positie in de samenleving (Ball 2003). Vrouwelijke personages besteden hun vrije tijd voornamelijk buitenshuis en hebben diverse vrijetijdsactiviteiten zoals reizen, deelname aan culturele evenementen, bezoeken van theater, bioscoop en attracties, bijwonen van danslessen, winkelen en het beoefenen van verschillende sporten. Bijeenkomsten met vrienden, in cafés, bars en disco's of in de open lucht zoals in parken worden ook gezien als belangrijke vrijetijdsbestedingen. Er worden in de leergang nauwelijks vrijetijdsactiviteiten van vrouwen genoemd die in hun huis plaatsvinden. In restaurants zijn vrouwelijke personages vaak vergezeld van vrienden en familieleden.

Voorbeelden: Maria doet drie keer per week bodyshape bij sportschool Jumping Feet, Annemarie schrijft een verjaardagskaartje aan haar vriendin Mihriban, mevrouw Van Veen feliciteert mevrouw de Vos met haar verjaardag, man en vrouw eten in een restaurant, drinken een glas wijn thuis, Jasmin gaat naar een belangrijk diner, vriendinnen winkelen gezellig in een meubelwinkel, Anna gaat met kerst naar Aruba, Milena nodigt Thomas uit om bij haar te komen eten. Op de jaarlijkse trouwdag krijgt de vrouw vaak een bos bloemen van haar man en soms gaan ze samen in een restaurant eten, Ilse, manager, sport na haar werk en kijkt dan nog een uurtje televisie.

Hieruit moet blijken dat Nederlandse vrouwen een grote diversiteit aan vrijetijdsbestedingen hebben. Bovendien besteden vrouwen vaak hun vrije tijd samenmet mannelijke en vrouwelijke vrienden, familieleden en partners. 


\section{Uiterlijk}

Het uiterlijk is voor de in de leergang geïntroduceerde vrouwen en mannen even belangrijk. Anna gaat met kerst naar Aruba: "Het is erg warm op Aruba. Ik draag dan een kort rokje met een T-shirt. Heerlijk!" (Code Plus 2: 143). In tegenstelling tot Sylvia, die uit Spanje komt, maakt ze zich geen zorgen over haar uiterlijk in haar vrije tijd. Anna geeft de voorkeur aan het dragen van comfortabele kleding daar waar Sylvia de voorkeur geeft aan chique en trendy kleding. Sylvia vertelt over het verschil in de kledingstijlen van de Nederlandse en de Spaanse vrouwen, vooral op feestdagen: "Op feestdagen trek ik een avondjurk aan. (...) In Spanje kopen vrouwen al in november hun kerstkleding. Kerst in een spijkerbroek? $\mathrm{O}$, nee, dat kan echt niet" (Code Plus 2: 142-143). Anna is van mening dat er geen specifieke regels of normen gelden voor kledingstijlen in de vrije tijd of op feestdagen. Voor haar is de vrije tijd een deel van haar leven waarin ze kan dragen wat ze wil. Bij hun dresscodes houden velen van de afgebeelde vrouwen geen rekening met de verwachtingen van anderen.

\section{Bekende (Nederlandse) vrouwen}

Bekende (Nederlandse) vrouwen verschijnen in de leergang niet als hoofdpersonages die centraal in een tekst staan, maar worden slechts als bijfiguren geïntroduceerd. De leergang bevat verwijzingen naar vrouwen die bekend zijn op verschillende gebieden, zoals prinses Máxima (de naam van een basisschool, Code Plus 1: 102) of van succesvolle vrouwelijke artiesten als Trijntje Oosterhuis, een van de meest geprezen en veelzijdige zangeressen van Nederland (Code Plus 2: 120) en Pien Straesser, een bekende sopraan (Code Plus 2: 121). Daarentegen staan mannelijke personages een aantal malen centraal: Rembrandt, Van Gogh, Mondriaan, Ali B. De representatie van bekende personen begunstigt dus mannelijke personages.

\section{Multicultureel perspectief}

In de geselecteerde leergang komen vrouwelijke personages met diverse etnische en culturele achtergronden in beeld. Op de cover van Code Plus 1 staat een jonge, moderne vrouw afgebeeld.

Etnische en culturele diversiteit komt aan bod door de presentatie van personages als Dewi Chen van Aziatische afkomst, Layla, 20 jaar, die op zoek is naar een huurwoning met haar partner Mohammed, Sylvia, een Spaanse die de dresscodes in Nederland en Spanje vergelijkt, Neylan van Turkse afkomst die in Nijmegen studeert, Malika, 50 jaar, uit Marokko die met haar familie sinds de jaren 
'80 in Nederland woont, Filiz die later graag naar de universiteit wil, Margreth de Vries-Wilson, een Australische die met een Nederlander getrouwd is.

Interpersoonlijke relaties als vriendschap tussen vrouwen met verschillende culturele achtergronden worden ook vermeld (Annemarie schrijft een verjaardagskaart aan haar vriendin Mihriban). Shakila en Jelena vertellen over hun cursus Nederlands en zijn zich bewust van de belangrijke rol van de interculturele communicatie: "Contact met Nederlanders is heel belangrijk. Dan leer je niet alleen de taal, maar ook hoe de cultuur is".

\section{Conclusie}

De vrouwelijke personages in de geanalyseerde leergang Nederlands voor andertaligen zijn duidelijk zichtbaar en worden door de methodes in 'dual roles', 'role switching' en 'role blending' op verschillende locaties binnen en buiten de huiselijke sfeer in diverse rollen geportretteerd (Lundstrom \& Sciglimpaglia 1977).

Zoals eerder vermeld, is die zich wijzigende rolverdeling tussen mannen en vrouwen in de Nederlandse maatschappij snel geëvolueerd en deze verandering komt ook in de leergangen Nederlands voor anderstaligen aan bod. In de 21e eeuw zijn de gezinsstructuren vervaagd en er is geen eenduidige rolverdeling terug te vinden. Er zijn voorbeelden van 'dual roles' waarbij vrouwen en mannen zowel in hun stereotiepe als niet-stereotiepe rol worden afgebeeld zoals Pieter die als arts werkt, boodschappen doet en voor zijn gezin kookt. In de agenda van Eddy staan naast afspraken met zijn cursisten ook afspraken die met de verzorging van zijn kinderen zijn verbonden.

Door 'role switching' worden vrouwen en mannen getoond in hun niet-stereotiepe rol. Een aanzienlijk aantal personages wordt door vanuit 'role blending' geportretteerd waarbij mannen en vrouwen in gender-neutrale rollen getoond worden. Op basis van de resultaten van kwantitatieve en kwalitatieve analyse kan Code Plus worden beschouwd als een genderevenwichtige leergang Nederlands voor anderstaligen, waarin geen specifieke mannenwereld wordt getoond.

\section{Bibliografie}

Ball, Stephen J. (2003): Class strategies and the education market, the middle classes and social advantage. London: Routledge.

Cottle, Simon (2000): Ethnic Minorities and the Media: Changing Cultural Boundaries. Buckingham: Open University Press. Laatst geraadpleegd op 3.03.2017 (http://www.mheducation. co.uk/openup/chapters/0335202705.pdf).

Geertz, Clifford (1983): Local Knowledge: Further Essays in Interpretive Antropology. New York: Basic Books. 
Kellner, Douglas (1995): Media Culture: Cultural Studies, Identity and Politics between the modern and the post-modern. London: Routledge.

Litosseliti, Lia \& Sunderland, Jane (ed.) (2002): Gender Identity and Discourse Analysis. Amsterdam/Philadelphia: John Benjamins.

Lundstrom, William J. \& Sciglimpaglia, Donald (1977): "Sex role portrayals in advertising. Are women and men critical of the way they are shown in ads, and how does this affect their attitudes towards products?" In: Journal of marketing 41, 3: 72-79.

Malik, Sarita (2002): Representing Black Britain: Black and Asian Images on Television. London: Thousand Oaks / New Delhi: Sage.

McQuail, Denis (2010): McQuails' Mass Communication Theory, $6^{\text {th }}$ edition. London: Sage. Laatst geraadpleegd op 3.03.2017 (http://www.gbv.de/dms/ilmenau/toc/613068874.PDF).

Porreca, Karen L. (1984): "Sexism in Current ESL Textbooks". In: TESOL Quarterly 18, 4: 705724.

Rifkin, Benjamin (1998): "Gender Representation in Foreign Language Textbooks: A Case Study of Textbooks of Russian”. In: The Modern Language Journal 82, 2: 217-236.

Schmitz, Betty (1975): "Sexism in French Language Textbooks". In: Lafayette, Robert C. (ed.): The Cultural Revolution in Foreign Language Teaching, Skokie (Ill.): National Textbook Co., 119-130.

Sunderland, Jane (ed.) (1994): Exploring Gender: Questions and Implications for English Language Education. New York: Prentice Hall.

Ven, Chris van der \& De Dreu, Carsten (2017): Denkfouten over diversiteit. Electronische presentatie van het voorgenomen project, laatst geraadpleegd op 19.10.2017 (http://www.innovatiefinwerk.nl/projecten/denkfouten-over-diversiteit).

Elissaveta Manolova Maciel (*1973) heeft een minor Nederlands gedaan bij haar masterstudie germanistiek. Daarnaast deed zij een master Interculturele Communicatie. Sinds 2006 is zij docente Nederlands als Vreemde Taal aan de Sofia Universiteit "St. Kliment Ohridski" (Bulgarije) bij het Departement voor Germanistiek en Scandinavistiek en het Departement voor Taalonderwijs en Internationale studenten. Daarnaast is zij werkzaam als freelance vertaler-tolk en taaladviseur.

e-mail: elimanolova@abv.bg 